\title{
A SIMPLE VAPORIZER IMPROVISED FROM A CARBON DIOXIDE ABSORBER CANISTER
}

\author{
J.W.R. McInTyre AND J.G. PuRdell-LeWIS
}

\begin{abstract}
A BSTRACT
An empty British Oxygen Company (B.O.C.) Mk. 4 carbon dioxide absorption cannister was modified for use as a vaporizer by placing a layer of flannelette bandage over the horizontal perforated septum and adding a base plate with an exit port for anaesthetic vapour. Aliquots of liquid anaesthetic were injected from a syringe through the top of the cannister and vaporised by air drawn through the cannister. Laboratory testing showed that this could be a useful way of administering inhalational anaesthesia in the absence of compressed gas supply.
\end{abstract}

\section{KEY WORDS: EQUIPMENT, vaporizer.}

MANY EXAMPLES of apparatus employing air as the carrier gas for the vapour of a volatile anaesthetic agent have been manufactured. Probably the most extensively stockpiled in various countries is the E.M.O. apparatus. ${ }^{1,2}$ However, such systems may not be readily available when they are required and when it is necessary to improvise an inhalational anaesthesia delivery system. Our purpose is to describe the adaptation of a readily available piece of equipment as a vaporizer and to remind anaesthetists of important differences in the situation when the cylinders of oxygen are not available.

The item of equipment used as a vaporizer was an empty canister from a British Oxygen Company (B.O.C.) Mk. 4 carbon dioxide absorber. This is cylindrical and placed vertically is $18 \mathrm{~cm}$ high, $13 \mathrm{~cm}$ in diameter and has a multiperforated septum located horizontally half-way down. Its volume is approximately $1700 \mathrm{ml}$. For use as a vaporizer the additions made were a layer or more of cotton bandage (Flannelette, McLean Converting Hospital Division, Toronto) resting on the septum, and a base plate $0.5 \mathrm{~cm}$ thick with an exit port $15 \mathrm{~mm}$ in diameter. Liquid anaesthetic was introduced by rapidly injecting aliquots from a syringe via a 22 gauge needle through the top of the cannister toward the centre of the flannelette. The vaporizer was to be used as a "draw over" model in conjunction with a self inflating resuscitation bag and a non-rebreathing valve (Figure 1).

The performance of the vaporizer was tested in the laboratory using a Harvard animal respirator

J.W.R. McIntyre, F.R.C.P.(C); J.G. Purdell-Lewis, F.R.C.P.(C): Department of Anaesthesia, University of Alberta, Edmonton, Alberta.

Canad. Anaesth. Soc. J., vol. 28, no. 2, March 1981

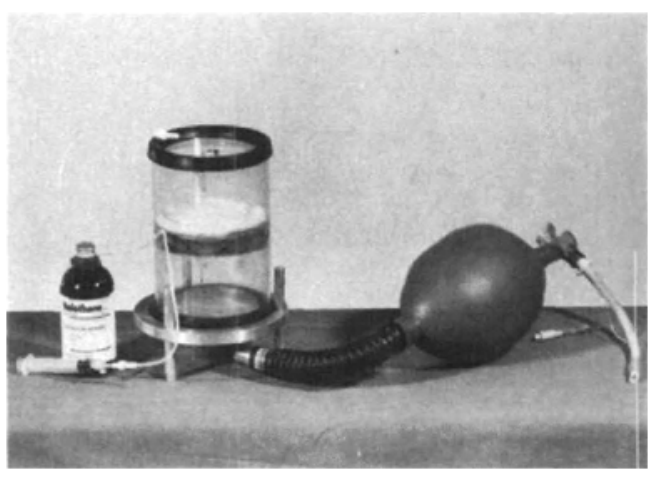

FIGURE 1 Vapour delivery system assembled for use.

pump to draw air through it and a halothane meter (Cavitron Model 73) to measure the concentration of halothane delivered. Variables of particular interest while using the vaporizer were the volume of air employed for ventilation, the quantity of liquid halothane injected, the number of layers of flannelette used as a vaporizing surface, and resistance to flow through the vaporizer. All experiments were done at approximately $21^{\circ} \mathrm{C}$. room temperature, barometric pressure $93.1 \mathrm{kPa}$ ( $700 \mathrm{~mm} \mathrm{Hg}$ ), a relative humidity of 30 per cent, and employing a respiratory rate of $12 /$ minute. The resistance to air flow for the duration of the experiments was found not to be clinically significant (Figure 2). The delivery of halothane vapour was influenced by the number of layers of: flannelette (Figure 3) and by the volume of halothane injected (Figure 4). The volume of ventilation (air drawn through the vaporizer) has a marked effect on halothane delivery (Figure 5), but the concentration was well maintained for the duration of the experiment (Figure 6). 


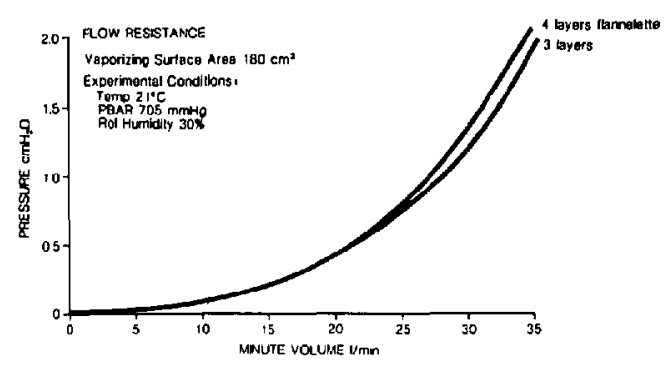

Figure 2 Resistance to airflow through the vaporizer.

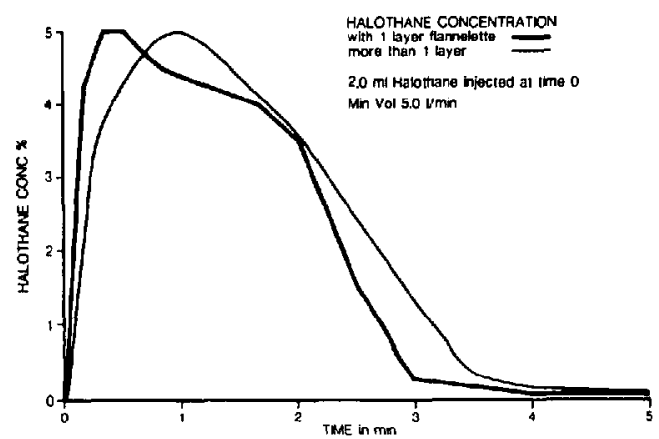

Figure 3 Halothane delivery from the vaporizer when $2.0 \mathrm{ml}$ was introduced while air was drawn through it at $51 / \mathrm{min}$.

In discussing this drug delivery system it should be stated that the vaporizer design is similar in appearance to the Denis Browne "Top Hat" , ${ }^{3}$ though in use it is more akin to an item familiar to World War II anaesthetists - the Flagg can. ${ }^{4}$ In a review of equipment employed in the early days of anaesthesia Thomas ${ }^{5}$ has described many related devices. As far as the vaporizing surface is concerned its character is of considerable importance. The classic experiments were performed by Hewitt \& Symes $^{6}$ in 1912. They found a double layer of flannelette offered an advantage over a single layer.

Most contemporary anaesthetists are unfamiliar with the "open drop" or "rag and bottle" technique of liquid anaesthetic delivery in which the drug is dropped on to gauze or flannelette stretched over a metal frame held over the patient's face, perhaps incurring a degree of rebreathing. The frames are unlikely to be available. The technique proposed here utilizes readily available equipment and abolishes the problem of rebreathing expired gases.

Though air unsupplemented by oxygen has been successfully used as a vehicle for anaesthetic vapours for more than a century, it is a novelty for many anaesthetists and justifies comment.

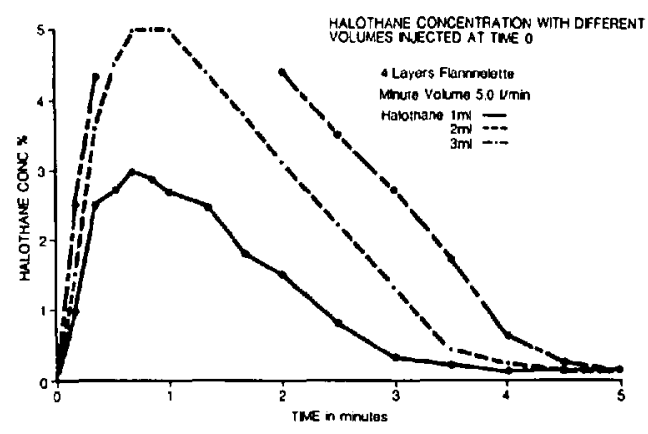

FigURE 4 Influence of volume of liquid halothane introduced and the thickness of the vaporizing surface on the halothane delivery from the vaporizer.

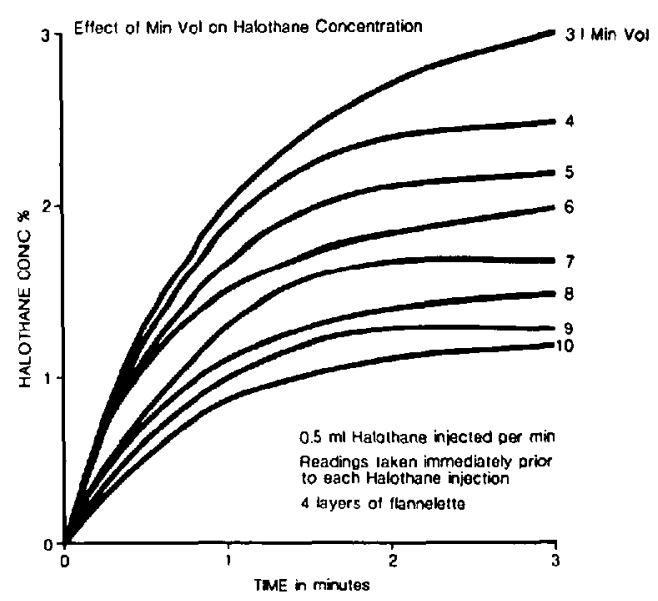

Figure 5 The effect of variations in volume of air drawn through the vaporizer on delivery of halothane vapour from it.

EFFECT OF REPEAT INJECTIONS OF HALOTHANE
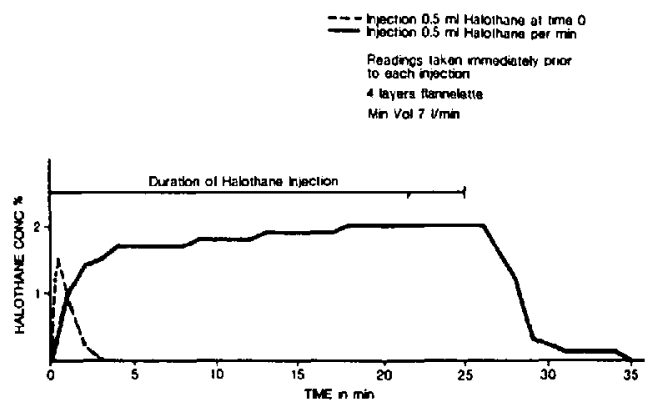

Figure 6 Halothane vapour delivery from the vaporizer following serial injections of liquid halothane.

During induction of anaesthesia arterial oxygen saturation diminishes rapidly if apnoea occurs (Figure 7), so tracheal intubation must be achieved rapidly. Similarly restoration of spon- 
ARTERIAL OXYGEN SATURATION \& TENSION DUANG APNEA

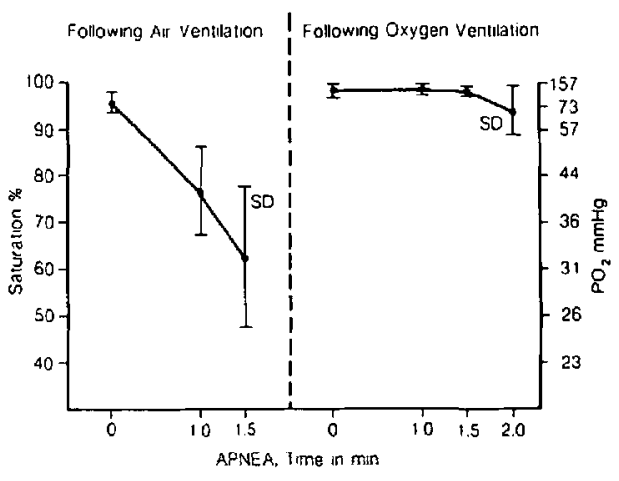

Alle, WEIT ZNF 8 Cl at

Anerithesiology $2062461959^{\circ}$

Figure 7 Comparison of the effects of apnoea on arterial oxygen saturation following ventilation with air or oxygen.

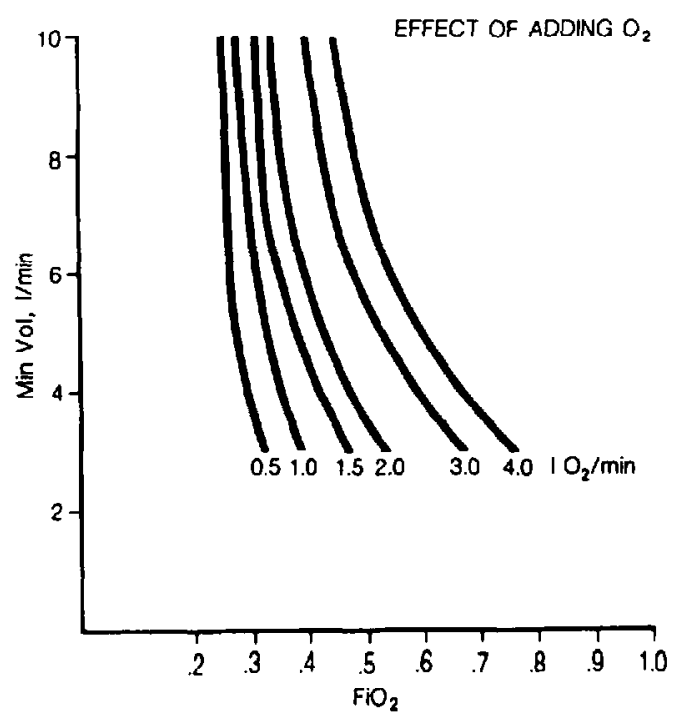

Figure 8 Effect on the delivered $\mathrm{F}_{10}$ of adding oxygen to air drawn through the vaporizer.

taneous respiration at the termination of artificial ventilation cannot be easily achieved without causing hypoxia. Cole and Parkhouse ${ }^{7}$ have reviewed blood oxygen saturation during anaesthesia with volatile agents including ether, trichlorethylene, halothane, and the azeotropic halothane-ether mixture vaporized in room air. They state that air is a satisfactory vehicle for most patients but emphasize that respiration must never be obstructed, depressed, or inadequate. Such a view has received qualified support from other sources..$^{4.9 .10}$ Ikezono, et al. ${ }^{8}$ state that when air is the diluent artificial ventila- tion is desirable if 95 per cent oxygen saturation is to be achieved consistently; but Mushin has stated that an inspired oxygen of $30-50$ per cent is necessary during controlled respiration. " Nurn has clearly indicated the need during general anaesthesia for increasing the inspired oxygen concentration above that of atmospheric air. ${ }^{12}$ It appears that it is better for patients if air is supplemented with oxygen, should this be possible. In our experiments supplementing air with oxygen at a flow of $1.5 \mathrm{I} / \mathrm{min}$ provided an $\mathrm{FIO}_{2}$ of not less than 0.3 over a wide range of minute volumes (Figure 7),

In conclusion, an empty B.O.C. Mk. 4 carbon dioxide absorber cannister removed from the mounting and with the addition of some flannelette and a base plate with exit port can function satisfactorily as a vaporizer. However, creation of a similar vaporizer out of such other materials as may be available should be done with caution, if halogenated anaesthetic agents are to be used, as interaction between the drug and the plastic or the metal ${ }^{13}$ may occur.

\section{REFERENCES}

1. Boulton, T.B. Anaesthesia in difficult situations. Anaesthesia 2l: 513 (1966).

2. Epstein, H.G. \& Macintosh, Sir Robert. An anaesthetic inhaler with automatic thermocompensation. Anaesthesia II:83 (1956).

3. Browne, Denis. Anaesthesia for tonsillectomy. Br. Med. J. 11:632 (1928).

4. Flagg, P.J. The Art of Anaesthesia. Philadelphia J.P. Lippincott Co. 1939.

5. ThOmas K. BRYN. The development of anaesthesia apparatus. Blackwell Oxford, Ist Edition, 1975.

6. Hewitt, Sir Frederick \& Symes, W. Legge. On the percentages of ether vapour administered in so-called "open ether" methods. Lancet $1: 215$, 1912.

7. Cole, P.V.\& PARKhouse, James. Clinical experience with the E.M.O. inhaler. Post Grd. Med. J. 39: 476 (1963).

8. Ikezono, E., Harmel, M.H. \& King, B.D. Pulmonary ventilation and arterial oxygen saturation during ether-air anesthesia. Anesthesiology 20:597 (1959).

9. Papantony, M. \& Landmesser, C.M. Pottable unit for Fluothane in Air Anesthesia ("PUFFA"). Anesthesiology 2I: 768 (1960).

10. Poppelbaum, H.F. Rediscovery of air for anaesthesia in thoracic surgery. Proc. Roy. Soc. Med. 53: 289 (1960).

11. Mushin, W.W. Discussion. Proc. Roy. Soc. Med. 53: 294 (1960).

12. NunN, J.F. Applied Respiratory Physiology. London, Butterworths (1969), pg. 294.

13. EPSTEIN, H.G. Inhalers used in trials for administering mixture of fluothane vapour with air or medical gases. Br. Med. J. 2: 489 (1957). 


\section{RÉSUMÉ}

Un canister d'absorption de gaz carbonique fabriqué par la British Oxygen Company a été modifié de façon à le transformer en vaporisateur en plaçant une couche de flanelle de coton sur la séparation perforée et en y ajoutant une plaque de fond avec une ouverture pour la sortie de la vapeur anesthésique. De petites quantités d'anesthésique liquide ont été injectés à l'aide d'une seringue par la partie supérieure et vaporisées dans l'air aspiré dans le canister. Des épreuves de laboratoire ont montré que ce dispositif pourrait être une méthode utile pour administrer les agents d'inhalation en l'absence de gaz comprimé. 